\title{
Awareness on Narcotic Substance Abuse Among Adolescents
}

\author{
Haripriya. $R^{1}$ and Dhanraj Ganapathy ${ }^{2}$ \\ ${ }^{1}$ Haripriya.R Saveetha Dental College Saveetha Institute of Medical and \\ Technical Sciences Saveetha University Chennai 77, India \\ ${ }^{2}$ Professor and Head of the Department Saveetha Dental College and Hospitals Saveetha \\ Institute of Medical and Technical Sciences Saveetha University, Chennai 77, India
}

\section{ABSTRACT}

Substance abuse is a common phenomenon in the world and has invaded human society as the most important social damage. Adolescent age is the transition period where people tend to begin many unhealthy behaviours that represent major public health problems. Adolescents take up various habits like smoking, alcohol, drug abuse, etc that has a major impact on individuals, families as well as the community. It contributes to the social, mental and physical health problems of an individual at an early age. It also leads to consequences like unemployment, aggressive behaviour, violence in adulthood.In the present study, an online questionnaire was prepared and circulated through an online portal among adolescents. A total of 100 adolescents were included in the study among which 65 were male and 35 were female.The participants in the study were categorized in the age group of below 15 years, 15 - 18 years and above 18 years. The results retrieved from the survey were tabulated and analysed using SPSS software (Version 23). From this study, it was observed that the majority of adolescents were aware of narcotic substance abuse and its ill effects. An early intervention and awareness on the ill effects of narcotic substance abuse to adults plays an important role in prevention.

KEY WORDS: SUBSTANCE ABUSE, ADOLESCENCE, DRUGS, HEALTH, AWARENESS.

\section{INTRODUCTION}

Substance abuse is a global threat for public health and social concern. With the evolving globalisation and various lifestyle changes, an increase in the acceptance of ill habits is clearly seen in low and middle income countries specifically in adolescents and adults(Shelton, Harvin and White, 2006). Adolescence is a crucial period where people tend to begin with various unhealthy behaviours

\section{ARTICLE INFORMATION}

*Corresponding Author: dhanraj@saveetha.com

Received 17th June 2020 Accepted after revision 10th August 2020 Print ISSN: 0974-6455 Online ISSN: 2321-4007 CODEN: BBRCBA

Thomson Reuters ISI Web of Science Clarivate Analytics USA and Crossref Indexed Journal

\section{Clarivate}

NAAS Journal Score 2020 (4.31) SJIF: 2020 (7.728)

A Society of Science and Nature Publication,

Bhopal India 2020. All rights reserved.

Online Contents Available at: http//www.bbrc.in/

Doi: http://dx.doi.org/10.21786/bbrc/13.7/28 and substance use is one among them(Sarangi, Acharya and Panigrahi, 2008). Adolescents are more vulnerable and are at high risk of problems related to substance abuse.(So and Wong, 2006). It has a major impact on individuals, families, society, etc. It contributes to the social, physical and mental health problems. Unhealthy behaviours like smoking, alcohol, and drug use tend to begin at the adolescent age. It has positive association with increased morbidity and mortality and represents as one of the major public health challenges(Henkel, 2011). Social threats like poor health, unemployment, accidents, mental illness, suicide, etc have drug misuse as one of the contributing factors(World Health Organization, 2015).

Factors like socioeconomic status, peer group influence, genetic predisposition towards drug addiction, poor quality of parenting enhances the risk of initiation of 
substance abuse(Abuse and US Department of Health \& Human Services; National Institute on Drug Abuse, 2001). An early intervention, awareness and knowledge on the harmful effects of narcotic substances greatly reduces the risk factor of drug abuse among adolescents ('Programs for the Prevention of Suicide Among Adolescents and Young Adults', 1994; Gould et al., 2003; Busby et al., 2020). Various reasons like lack of love and safety feeling in families, being in conflict with peer group or influence of peer groups and the need for acting opposite to the social rules, etc. tend to be the causes of substance use among adolescents(Nieradko et al., 2002). Previously our department has published extensive research on various aspects of prosthetic dentistry ('Evaluation of Corrosive Behavior of Four Nickel-chromium Alloys in Artificial Saliva by Cyclic Polarization Test:An in vitro Study', 2017; Ganapathy, Kannan and Venugopalan, 2017; Jain, 2017a, 2017b; Ranganathan, Ganapathy and Jain, 2017; Ariga et al., 2018; Gupta, Ariga and Deogade, 2018; Anbu et al., 2019; Ashok and Ganapathy, 2019; Duraisamy et al., 2019; Varghese, Ramesh and Veeraiyan, 2019), this vast research experience has inspired us to research about awareness on narcotic substance abuse among adolescents.

\section{MATERIAL AND METHODS}

The present study was a questionnaire based study. A questionnaire was prepared and circulated through an online portal among adolescents aged between $12-20$ years. The data collection was done by a simple random sampling method. A total of 100 adolescents attended the survey among which 65 were male and 35 were female. The questionnaire included demographic details like age, gender, etc, and questions on awareness and knowledge on various ill effects on narcotic substance abuse and addiction among adolescents. The results obtained from the survey were tabulated and analysed by descriptive statistics with chi square test using SPSS software (version 23). The results were analysed and represented graphically.

\section{RESULTS AND DISCUSSION}

The responses retrieved from the questionnaire were tabulated, analysed and graphical representation was done using the SPSS software. A total of 100 respondents submitted the completed survey among which 65 were male respondents and 35 were female respondents. Among the 100 respondents, 13\% were below 15 years of age, 55\% were in the $15-18$ age group and 32\% were above 18 years of age. [Figure 1] When enquired about the awareness on narcotic substances, $76 \%$ of the adolescents were aware of narcotic substances while $24 \%$ of the adolescents were not aware. When enquired about the causes of use of narcotic substances, the respondents below 15 years of age were not aware. In the age group of 15 - 18 years, 3\% responded that it is because of not being content in life, 13\% responded that it is for fun and amusement, $16 \%$ responded that it is due to peer pressure, $17 \%$ agreed with the statement that there is no harm in trying drugs once and 6\% of them were not aware. In the age group of above 18 years, $2 \%$ felt that it is because of not being content in life, $7 \%$ responded that it is for fun and amusement, 15\% responded that it is due to peer pressure, $8 \%$ felt that it is because of the attitude of there is no harm in trying drugs once. When the chi square test was done and the association between age and awareness on causes of narcotic substance use was analysed, p value was $0.00(<0.05)$ showing statistical significance. [Figure 2] When the awareness of ill effects of the narcotic substance use on health was analysed, the majority of the respondents below 15 years were not aware( $9 \%$ ) while $4 \%$ were aware. Among the respondents in the age group of 15 - 18 years, 44\% were aware and $11 \%$ were not aware. In the age group of above 15 years, 18\% were aware of the ill effects and $14 \%$ were not aware.

Figure 1: Bar graph representing the different age group of the participants in the study. X- axis represents the different age groups and $y$-axis represents the number of participants. In this study, 13\% of the participants were below 15 years of age, 55\% were in the age group of 15 - 18 years and $32 \%$ were above 18 years

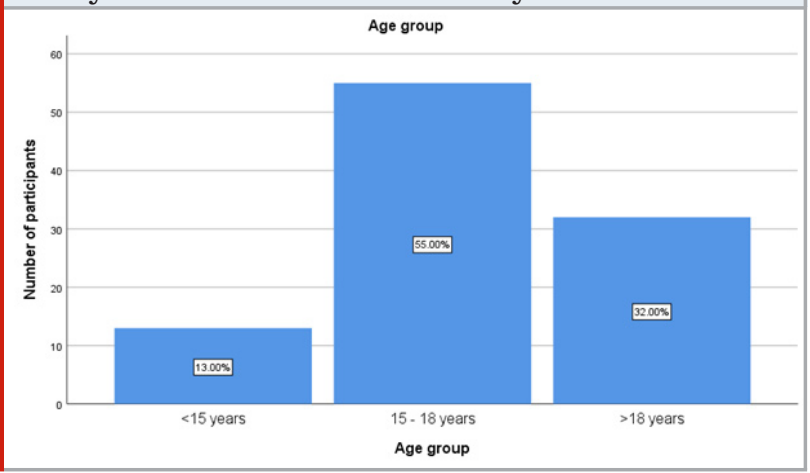

Figure 2: Bar graph representing the association between age groups and the causes of narcotic substance use among adolescents. $\mathrm{X}$ axis represents the different age groups and $y$-axis represents the number of participants. The participants in the age group of above 15 years were more aware of the causes of narcotic substance use. There was a significant statistical difference between age and awareness on causes of narcotic substance use. (Pearson's chi square test, $\mathrm{p}>0.05$ )

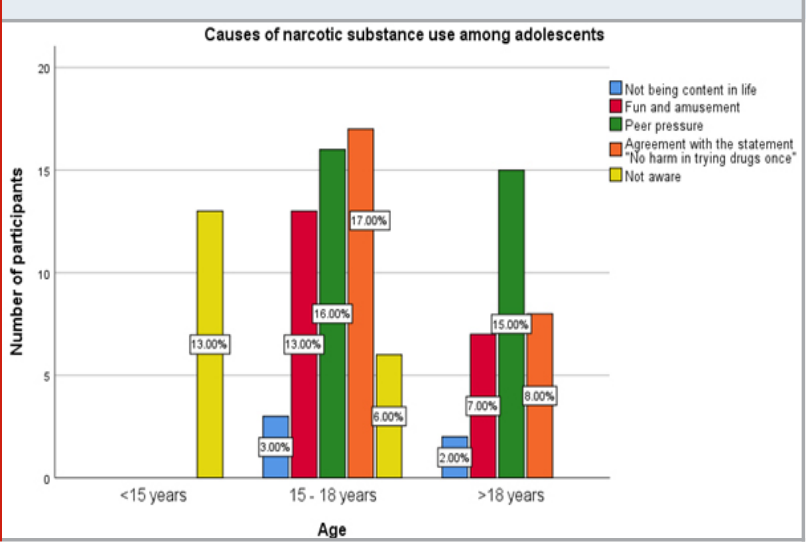


When the chi square test was done and the association between age and awareness on ill effects of narcotic substance use on health was analysed, $p$ value was found to be $0.00(<0.05)$ showing statistical significance. [Figure 3] When the awareness on psychological and social effects due to narcotic substance use was analysed, the respondents below 15 years of age were not aware, among the respondents in the age group of 18 - 15 years, $39 \%$ were aware and 16\% were not aware. Among the respondents in the age group of above 18 years, $28 \%$ were aware and 6\% were not aware. When the chi square test was done and the association between age and awareness on psychological and social effects due to narcotic substance use was analysed, $p$ value was found to be $0.00(<0.05)$ showing statistical significance. [Figure 4] When the awareness on law against narcotic substances use "Narcotic drugs and psychotropic substances act" was analysed, the respondents below 15 years were not aware of it , in the age group of $15-18,13 \%$ were aware and $42 \%$ were not aware of the law.

Figure 3: Bar graph representing the association between age groups and the awareness on ill effects of narcotic substance abuse on health among adolescents. $\mathrm{X}$ axis represents the different age groups and $y$-axis represents the number of participants. The participants in the age group of above 15 years were more aware of the ill effects of narcotic substance use. There was significant statistical difference between age and awareness on ill effects of narcotic substance use. (Pearson's chi square test, $p$ value $>0.05$ )

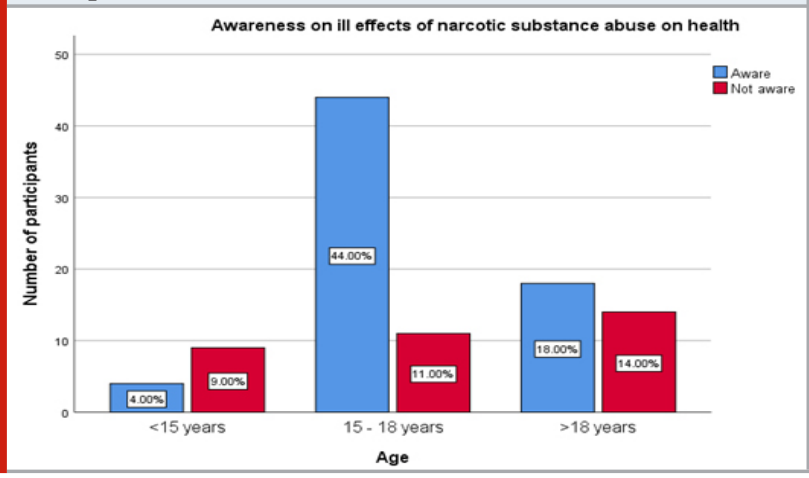

In the age group of above 18 years, $11 \%$ were aware of the law and 21\% were not aware of it. When the chi square test was done and the association between age and awareness on law against narcotic substance use was analysed, $p$ value was found to be $0.00(<0.05)$ showing statistical significance. [Figure 5] When the awareness on addiction due to narcotic substance abuse was analysed, among the respondents below 15 years of age, $2 \%$ were aware of it and 11\% were not aware of it. In the age group of 15 - 18 years, 38\% were aware and $17 \%$ were not aware. In the age group of above 18 years, $28 \%$ were aware and $4 \%$ were not aware. When the chi square test was done and the association between age and awareness on addiction due to narcotic substance use was analysed, $p$ value was found to be $0.00(<0.05)$ showing statistical significance. [Figure 6]
Figure 4: Bar graph representing the association between age groups and the awareness of psychological and social effects due to narcotic substance abuse among adolescents. $\mathrm{X}$-axis represents the different age groups and $\mathrm{y}$-axis represents the number of participants. The participants in the age group of above 15 years were more aware of psychological and social effects due to narcotic substance use. There was a significant statistical difference between age and awareness on psychological and social effects due to narcotic substance use. (Pearson's chi square test, $p$ value $>0.05$ )

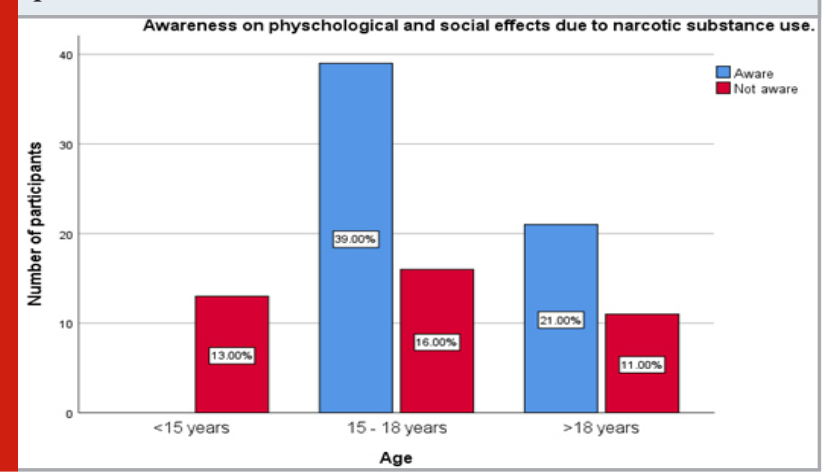

Figure 5: Bar graph representing the association between age groups and the awareness on Narcotic Drugs and Psychotropic Substance abuse Act among adolescents. $\mathrm{X}$-axis represents the different age groups and $\mathrm{y}$-axis represents the number of participants. Majority of the participants in different age groups were not aware of the law against narcotic substance abuse. There was significant statistical difference between age and awareness on Narcotic Drugs and Psychotropic Substance abuse Act among adolescents. (Pearson's chi square test, p value $>0.05$ )

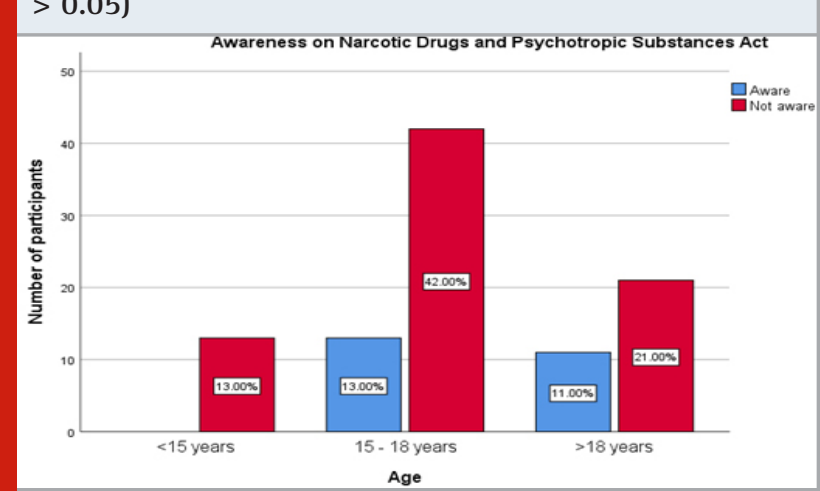

Adolescence is recognized as the period during which onset of change in behaviours occur. Unhealthy behaviours like drinking, smoking and illicit drug use begin during adolescence.(Das et al., 2016) The abuse of alcohol and illicit drugs are a major health problem worldwide.(Adolescent Drug Use Prevention: Common Features of Promising Community Programs, 1994) Prevention of substance abuse among adolescents requires awareness that focuses on the youngsters who are more prone to substance use and addiction. This 
helps in greatly reducing the risk factors associated with drug use in adolescence. (Bukoski and US Department of Health and Human Services; National Institute on Drug Abuse, 1991) Preventive science states that negative health and psychological outcomes can be prevented by reducing the risk factors. Early intervention and awareness plays a key role in preventing substance abuse. (Hawkins and David Hawkins, 2002) The risk factors include poor parenting habits, poor communication, adverse childhood, loneliness, depression, peer influence, history of aggressiveness, violence, etc.

Figure 6: Bar graph representing the association between age groups and the awareness on addiction due to narcotic substance abuse. $X$ axis represents the different age groups and $y$-axis represents the number of participants. The participants in the age group of above 15 years were more aware of addiction due to narcotic substance use. There was a significant statistical difference between age and awareness on addiction due to narcotic substance use. (Pearson's chi square test, p value $>0.05$ )

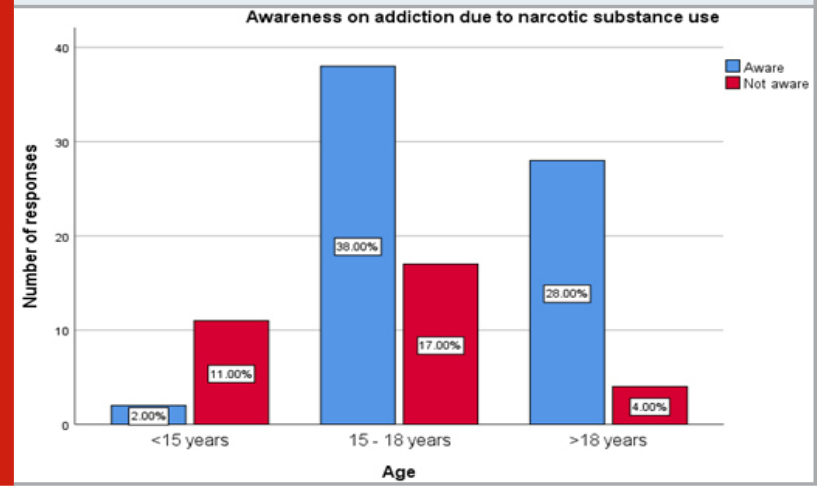

The prevention programs includes various aspects like family programs which includes parental monitoring and supervision that aims on enhancing the behaviour and reinforcing the harmful effects of drugs. (Kosterman et al., 2001) School programs help in working on self control, emotional awareness, communication, academic support, etc. Community programs which included clubs, schools, faith based organisations have beneficial effects on high risk families. (Epstein et al., 1995; Dishion et al., 2002) Survey based awareness programs play an essential role in prevention and they are cost effective too.(Chou et al., 1998; Spoth and Redmond, 2002; Hawkins, Ghiani and Baum, 2019) Previous studies state that adolescents have less knowledge on drug abuse, its effect on health, etc. (Wei et al., 1999; Epstein, Botvin and Diaz, 2001; Medrela-Kuder, 2007).

Some studies state that there is a positive relationship between knowledge and year of study, family income and drug abuse. Association between substance abuse and aggressive behaviour and violence were observed in previous studies. (Jindal and Gupta, 2004; Avila et al., 2005; Gilliland et al., 2006) In the present study, the majority of the adolescents were aware of the narcotic substance abuse and its ill effects. However, many were not aware of the laws and regulations against narcotic substance abuse. There was significant association between age and awareness on the physical, psychological and overall health effects due to narcotic substance abuse.

\section{CONCLUSION}

From this study we can conclude that adolescents are aware of the harmful effects of use of narcotic substances. However, more awareness must be created among adolescents in a larger population about narcotic substance abuse. An early intervention and awareness on the ill effects of narcotic substance abuse at an early age helps in avoidance of such illicit habits and addiction.

\section{Conflict of Interest: Nil}

\section{REFERENCES}

Abuse, U. S. D. of H. \&t. H. S. N. I. on D. and US Department of Health \& Human Services; National Institute on Drug Abuse (2001) '2nd National Conference On Drug Abuse Prevention Research: A Progress Update', PsycEXTRA Dataset. doi: 10.1037/e313412004011.

Adolescent Drug Use Prevention: Common Features of Promising Community Programs (1994). DIANE Publishing.

Anbu, R. T. et al. (2019) 'Comparison of the Efficacy of Three Different Bone Regeneration Materials: An Animal Study', European journal of dentistry, 13(1), pp. 22-28.

Ariga, P. et al. (2018) 'Determination of Correlation of Width of Maxillary Anterior Teeth using Extraoral and Intraoral Factors in Indian Population: A Systematic Review', World Journal of Dentistry, 9(1), pp. 68-75.

Ashok, V. and Ganapathy, D. (2019) 'A geometrical method to classify face forms', Journal of oral biology and craniofacial research, 9(3), pp. 232-235.

Avila, L. et al. (2005) 'Asthma, current wheezing, and tobacco use among adolescents and young adults in Costa Rica', The Journal of asthma: official journal of the Association for the Care of Asthma, 42(7), pp. 543-547.

Bukoski, W. J. and US Department of Health and Human Services; National Institute on Drug Abuse (1991) 'A Framework for Drug Abuse Prevention Research', PsycEXTRA Dataset. doi: 10.1037/e496282006-003.

Busby, D. R. et al. (2020) 'Adolescents' Engagement with Crisis Hotline Risk-management Services: A Report from the Emergency Department Screen for Teen Suicide Risk (ED-STARS) Study', Suicide \& life-threatening behavior, 50(1), pp. 72-82.

Chou, C. P. et al. (1998) 'Effects of a community-based prevention program on decreasing drug use in high-risk adolescents', American journal of public health, 88(6), pp. 944-948.

Das, J. K. et al. (2016) 'Interventions for Adolescent Substance Abuse: An Overview of Systematic Reviews', 
Journal of Adolescent Health, pp. S61-S75. doi: 10.1016/j.jadohealth.2016.06.021.

Dishion, T. J. et al. (2002) 'Preventing early adolescent substance use: a family-centered strategy for the public middle school', Prevention science: the official journal of the Society for Prevention Research, 3(3), pp. 191-201.

Duraisamy, R. et al. (2019) ‘Compatibility of Nonoriginal Abutments With Implants: Evaluation of Microgap at the Implant-Abutment Interface, With Original and Nonoriginal Abutments', Implant dentistry, 28(3), pp. 289-295.

Epstein, J. A. et al. (1995) 'Social and personal factors in marijuana use and intentions to use drugs among inner city minority youth', Journal of developmental and behavioral pediatrics: JDBP, 16(1), pp. 14-20.

Epstein, J. A., Botvin, G. J. and Diaz, T. (2001) 'LINGUISTIC ACCULTURATION ASSOCIATED WITH HIGHER MARIJUANA AND POLYDRUG USE AMONG HISPANIC ADOLESCENTS', Substance Use \& Misuse, pp. 477-499. doi: 10.1081/ja-100102638.

Evaluation of Corrosive Behavior of Four Nickelchromium Alloys in Artificial Saliva by Cyclic Polarization Test:An in vitro Study' (2017) World Journal of Dentistry, 8(6), pp. 477-482.

Ganapathy, D. M., Kannan, A. and Venugopalan, S. (2017) 'Effect of Coated Surfaces influencing Screw Loosening in Implants: A Systematic Review and Meta-analysis', World Journal of Dentistry, 8(6), pp. 496-502.

Gilliland, F. D. et al. (2006) 'Regular Smoking and Asthma Incidence in Adolescents', American Journal of Respiratory and Critical Care Medicine, pp. 1094-1100. doi: 10.1164/rccm.200605-722oc.

Gould, M. S. et al. (2003) 'Youth suicide risk and preventive interventions: a review of the past 10 years', Journal of the American Academy of Child and Adolescent Psychiatry, 42(4), pp. 386-405.

Gupta, P., Ariga, P. and Deogade, S. C. (2018) 'Effect of Monopoly-coating Agent on the Surface Roughness of a Tissue Conditioner Subjected to Cleansing and Disinfection: A Contact Profilometric Study', Contemporary clinical dentistry, 9(Suppl 1), pp. S122S126.

Hawkins, J. D. and David Hawkins, J. (2002) 'Using prevention science to guide prevention action in communities', PsycEXTRA Dataset. doi: 10.1037/ e538812013-005.

Hawkins, S. S., Ghiani, M. and Baum, C. F. (2019) 'Associations Between State Tobacco Control Policies and Adolescent ENDS Use', Journal of public health management and practice: JPHMP, 25(6), pp. 529536.

Henkel, D. (2011) 'Unemployment and substance use: a review of the literature (1990-2010)', Current drug abuse reviews, 4(1), pp. 4-27.
Jain, A. R. (2017a) 'Clinical and Functional Outcomes of Implant Prostheses in Fibula Free Flaps', World Journal of Dentistry, 8(3), pp. 171-176.

Jain, A. R. (2017b) 'Prevalence of Partial Edentulousness and Treatment needs in Rural Population of South India', World Journal of Dentistry, 8(3), pp. 213-217.

Jindal, S. K. and Gupta, D. (2004) 'The relationship between tobacco smoke \& bronchial asthma', The Indian journal of medical research, 120(5), pp. 443-453.

Kosterman, R. et al. (2001) 'Childhood risk factors for persistence of violence in the transition to adulthood: a social development perspective', Violence and victims, 16(4), pp. 355-369.

Medrela-Kuder, E. (2007) '[Evaluation of the level of students' knowledge about psychoactive drugs]', Roczniki Panstwowego Zakladu Higieny, 58(2), pp. 453-458.

Nieradko, B. et al. (2002) '[Frequency analysis of the use of addictive substances by adolescents attending secondary schools in Sanok]', Wiadomosci lekarskie , 55 Suppl 1(Pt 2), pp. 818-824.

Programs for the Prevention of Suicide Among Adolescents and Young Adults' (1994) PsycEXTRA Dataset. doi: 10.1037/e546942006-001.

Ranganathan, H., Ganapathy, D. M. and Jain, A. R. (2017) 'Cervical and Incisal Marginal Discrepancy in Ceramic Laminate Veneering Materials: A SEM Analysis', Contemporary clinical dentistry, 8(2), pp. 272-278.

Sarangi, L., Acharya, H. P. and Panigrahi, O. P. (2008) 'Substance abuse among adolescents in urban slums of sambalpur', Indian journal of community medicine: official publication of Indian Association of Preventive Et Social Medicine, 33(4), pp. 265-267.

Shelton, A., Harvin, S. and White, J. (2006) 'Substance Abuse Prevention Program for Children and Adolescents in a Community-Based Clinic', Substance Abuse, pp. 21-25. doi: 10.1300/j465v26n03_05.

Spoth, R. L. and Redmond, C. (2002) 'Prevention Science', pp. 203-221. doi: 10.1023/a:1019946617140. Varghese, S. S., Ramesh, A. and Veeraiyan, D. N. (2019) 'Blended Module-Based Teaching in Biostatistics and Research Methodology: A Retrospective Study with Postgraduate Dental Students', Journal of dental education, 83(4), pp. 445-450.

Wei, H. et al. (1999) 'Alcohol consumption and alcohol-related problems: Chinese experience from six area samples, 1994', Addiction, pp. 1467-1476. doi: 10.1046/j.1360-0443.1999.941014673.x.

World Health Organization (2015) Core Competencies in Adolescent Health and Development for Primary Care Providers: Including a Tool to Assess the Adolescent Health and Development Component in Pre-service Education of Health-Care Providers. World Health Organization. 